\title{
Diphenylhydantoin effects on avoidance conditioning as a function of age and problem difficulty'
}

\section{BARBARA DOTY and ROSEANNE DALMAN, North Central College, Naperville, Ill. 60540}

Diphenylhydantoin, a common antiepileptic drug, facilitated acquisition and retention by rats treated prior to acquisition trials on discriminated and delayed avoidance tasks. Drug enhancement of performance was more prominent among aged than young rats, especially on the delayed task.

The drug diphenylhydantoin (dilantin) has long been known for its effectiveness in the treatment of human convulsive disorders. It has been successful in the control of all epilepses except petit mal, with relatively few side effects. The drug acts to block the tonic phase of electroconvulsive shock-induced seizures, and stabilizes the threshold of nerve cells against a wide variety of conditions which normally produce hyperexcitation (Toman, 1965).

Recently, dilantin has been used effectively in disorders other than epilepsy-in the treatment of hyperirritable, nonepileptic humans (Toman, 1966). Dilantin also may facilitate performance of aged, but not young rats on simple-avoidance tasks (Gordon, 1967). Since very little systematic animal research with dilantin is available, it is not clear what effect the drug would have on performance of more complex avoidance responses.

The present study was undertaken in order to determine how pretrial dilantin treatment affects the performance of young and aged rats attempting easy or difficult tasks.

\section{PROCEDURES}

Subjects were 180 hooded rats of Long-Evans stock equally distributed across three age groups. At the beginning of the experiment, Ss were 60 to 90,400 to 430 , or 700 to 730 days old. One-half of Ss in each group were males. One-third of the Ss in each age group were randomly assigned to one of two dilantin treatment groups and one-third to saline treatment in volumes equivalent to those administered drug groups. All injections were administered in double-blind fashion. Ss received 20 to $60 \mathrm{mg} / \mathrm{kg}$ subcutaneously in $2 \mathrm{cc}$ dextrose solution $30 \mathrm{~min}$ prior to daily trial blocks.

Ss in each treatment-dosage subgroup were randomly assigned either to a discriminated avoidance or to a delayed avoidance task. All Ss were trained to a criterion of seven out of 10 consecutive avoidance responses on acquisition trials. Ss ran retention trials to this criterion, without treatment, 10 days after completion of acquisition trials. Identical training procedures were employed on acquisition and retention trials. All training was conducted between 4 and 7 PM.

The apparatus was a four-compartment modified shuttle box which has been described in detail in a previous report (Doty, 1966). On the discriminated avoidance task, Ss were required to run to the lighted compartment of the apparatus within $5 \mathrm{sec}$ of the appearance of the light (the CS) to avoid shock to the feet (the UCS). Procedures for the delayed avoidance task were similar to the above, except that Ss were restrained from responding by a Plexiglas barrier for $2 \mathrm{sec}$ after termination of the CS. Shock was supplied by a 110-120 V ac Foringer power supply which delivered a footshock intensity of $1.5 \mathrm{~mA}$ through a grid shock scrambler.

\section{RESULTS}

Mean avoidances performed by all Ss, and some of the significant mean differences, are presented in Table 1. A 3 by 3 by 2 by 2 analysis of variance yielded a significant $F$ value for the main effects of Task Difficulty $(F=32.47, p<.001)$, and Trials $(F=48.93, p<.001)$, indicating that the two avoidance problems did represent different levels of difficulty, and that performance improved among most groups on retention trials on both tasks. A significant interaction appeared between Age and Task Difficulty $(F=10.78$, $\mathrm{p}<.01)$ primarily because old $\mathrm{Ss}$ in all treatment groups tended to perform poorly on the delayed avoidance task. The three-way interactions between Age, Task Difficulty and Trials was also significant $(F=19.49, p<.001)$ due to the greater retention by young $S s$ of the delayed avoidance problem. Other significant interactions appeared between Drug by Age by Task $(F=16.45, p<.001)$ as well as Drug by Age by Training $(F=10.53, p<.01)$. The four-way interaction among Age, Task, Drug Treatment, and Trials was also significant at the .001 level $(F=15.81)$. Application of $t$-tests and range tests provided the following points relevant to these interactions. Treatment with dilantin improved both acquisition and retention of avoidance responses as a function of increasing age. The performance of youngest Ss was unaffected by dilantin treatment except at the highest dosage level, at which retention of delayed avoidances was substantially improved. This effect might have been more pronounced if young control Ss had not retained the easier avoidances so well.

\section{DISCUSSION}

The results indicated that treatment with dilantin improved both acquisition and retention of avoidance responses as a

Table 1

Mean Avoidances Performed by All Subjects to a Criterion of 7 out of 10 Consecutive Avoidances

\begin{tabular}{|c|c|c|c|c|c|c|}
\hline \multirow[t]{3}{*}{ Age (days) } & \multirow{3}{*}{\multicolumn{2}{|c|}{ Treatment Group }} & \multicolumn{4}{|c|}{ Avoidance Task } \\
\hline & & & \multicolumn{2}{|c|}{ Acquisition } & \multicolumn{2}{|c|}{ Retention } \\
\hline & & & $\begin{array}{c}\text { Discriminated } \\
\text { Avoidance }\end{array}$ & $\begin{array}{c}\text { Delayed } \\
\text { Avoidance }\end{array}$ & $\begin{array}{c}\text { Discriminated } \\
\text { Avoidance }\end{array}$ & $\begin{array}{r}\text { Delayed } \\
\text { Avoidance }\end{array}$ \\
\hline $60-90$ & Dilantin & 1 & $51.2^{\neq}$ & 98.7 & 24.6 & 63.2 \\
\hline $60-90$ & & 2 & 48.9 & 99.3 & 24.2 & $53.2^{*}$ \\
\hline $400-430$ & & 1 & 52.6 & 94.2 & 21.6 & 74.6 \\
\hline $400-430$ & & 2 & 45.1 & $88.6^{*}$ & 20.2 & $68.1^{*}$ \\
\hline $700-730$ & & 1 & 45.8 & $130.2^{*}$ & 24.6 & $109.6 *$ \\
\hline $700-730$ & & 2 & $40.1^{*}$ & $134.3^{*}$ & $18.3^{*}$ & $115.8^{*}$ \\
\hline $60-90$ & Saline & & 48.6 & 91.5 & 25.8 & 65.3 \\
\hline $400-430$ & Saline & & 50.3 & 102.6 & 24.6 & 82.7 \\
\hline $700-730$ & Saline & & 53.4 & 151.3 & 29.5 & 135.2 \\
\hline
\end{tabular}

* Significantly smaller than mean obtained by saline-treated $S s$ of similar ages $(p<.01)$. $\neq N=8$ 
Table 1

Duncan's Multiple Range Test: Mean Percentage Scores

\begin{tabular}{lllllll}
\hline Group & $.15 \mu \mathrm{g}$ & $.05 \mu \mathrm{g}$ & $.125 \mu \mathrm{g}$ & $.075 \mu \mathrm{g}$ saline & $.10 \mu \mathrm{g}$ \\
Mean Percent- & -33.25 & -28.83 & -0.25 & 5.40 & 29.00 & 36.20 \\
age Score* & & & & & &
\end{tabular}

* Scores which are underlined by a common line do not differ significantly $(p=.05)$

df $=5 / 24, p<.06)$, but not with respect to the time scores $(F=1.62, d f=5 / 24, p>.10)$. A test for lieterogeneity of variance indicated that the data were homogeneous. The percentage scores were tested with Duncan's New Multiple Range Test, and the results are shown in Table 1. The . 10- $\mu \mathrm{g}$ group and the saline-injected controls did not differ, and both scored significantly higher than the $.05-\mu \mathrm{g}$ and $.15-\mu \mathrm{g}$ groups, which also did not differ from each other. The $.075-\mu \mathrm{g}$ and $.125 \mu \mathrm{g}$ groups scored neither significantly lower than the control and $.10 \mu \mathrm{g}$ groups nor significantly higher than the $.05-\mu \mathrm{g}$ and $.15-\mu \mathrm{g}$ groups.

\section{DISCUSSION}

Pretrial injection of eserine did not facilitate the learning of the task involved and, indeed, with the lowest and the highest dosages of the drug significantly impaired learning. Observation of the animals during testing indicated that the eserine-injected Ss appeared to be suffering from a motivational deficit in that they showed more fear and appeared to be more hesitant in exploring the apparatus during the initial 5-min period. However, the lack of significant differences among the time scores would appear to rule out performance deficits based on motivational differences as an explanation of the results. Also, it would be difficult to imagine why only the lowest and the highest dosages should have such an effect. While the explanation of the peculiar dosage effects awaits further research with a wider range of dosages, these results do not provide support for the hypothesis that learning efficiency, at least on the task used here, is positively correlated with increased ACh activity in the rat brain.

\section{REFERENCES}

BIENNETT, E. L., DIAMOND, M. (., KRECH, D., \& ROSENZWEIG, M. R. Chemical and anatomical plasticity of brain. Science, 1964, 146, $610-619$.

CARLTON, P. L. Cholinergic mechanisms in the control of behavior by the brain. Psychological Review, 1963, 70, 19-39.

DEUTSCII, J. A., \& DEUTSCH, D. Physiological psychology. Homewood, Ill.: Dorsey, 1966.

GLOW, P. H., RICIIARDSON, A., \& ROSE, S. Effect of reduced cholinesterase activity on the maintenance of an operant response. Journal of Comparative \& Physiological Psychology, 1967, 63, 155-157.

GLOW, P. H., \& ROSE, S. Cholinesterase levels and operant extinction. Joumal of Comparative \& Physiological Psychology, 1966, 61, 165-172.

HAMILTON, H. C., \& HARNED, B. K. The effect of the administration of sodium bromide to pregnant rats on the learning ability of the offspring. III. Three-table-test. Journal of Psychology, 1944, 18, 183-195.

LIBERMAN, R. Retinal cholinesterase and glycolysis in rats raised in darkness. Science, 1962, 135, 372-373.

REEVES, C. Cholinergic synaptic transmission and its relationship to behavior. Psychological Bulletin, 1966, 65, 321-335.

RICHARDSON, A. J., \& GLOW, P. H. Discrimination behavior in rats with reduced cholinesterase activity. Joumal of Comparative \& Physiological Psychology, 1967, 63, 240-246.

ROSENZWEIG, M. R. Environmental complexity, cerebral change, and behavior. American Psychologist, 1966, 21, 321-332.

ROSENZWEIG, M. R., KRECH, D., \& BENNETT, E. L. A search for relations between brain chemistry and behavior. Psychological Bulletin, 1960, 57, 476-492.

(Continued from page 109)

function of increasing age. The improvement was more pronounced in the aged rats than in the young rats, especially on the delayed avoidance task.

But basically, dilantin appears to improve avoidance performance of rats in a relatively nonspecific manner. Treatment enharces acquisition and retention of both discriminated and delayed avoidances by $S s$ at several age levels. Nevertheless, the delayed avoidance performance of aged Ss is most susceptible to treatment. The basis for these findings is unknown.

Independent determinations of the effects of delantin on pain-response thresholds and general activity did not reveal any alterations in these characteristics. And, at the dosages employed, drug toxicity, acute treatment effects, or disruptive side effects were highly improbable. Aged Ss attempting a difficult task may be characterized by a high anxiety level which impairs performance (Inglis, 1965; Welford, 1965). Thus, dilantin enhancement of avoidance performance may possibly be due to the drug reducing anxiety. Or, the drug may act more or less selectively on short-term memory processes. Aged Ss, who may be characterized by an immediate memory deficit, may be particularly handicapped on a delayed task (Doty, 1966; Inglis, 1965).

A possible mechanism of dilantin's effects on avoidance behavior is suggested by findings that the drug abolishes posttetanic potentiation (PTP). PTP is an apparent increase in synaptic excitability resulting from repetitive stimulation. Suppression of PTP may explain the clinical effectiveness of dilantin as well as recent findings that the drug reduces impulsiveness and distractibility in nonepileptic humans. A state of central hyperexcitability is hypothesized to characterize the aged brain (Welford, 1965; Inglis, 1965; Axelrod, 1963). This condition may be a preservation of electrophysiological activity following brain stimulation, which produces only "noise" in the system, and thus interferes with normal behavioral functioning. If this approach is accurate, then the improved conditioned avoidance performance of aged Ss given dilantin may reflect a more normal state of central electrical activity, possibly brought about by the suppression of abnormal PTP states. It is obvious that more research is needed before these highly speculative statements can be given much credence.

\section{REFERENCES}

AXELROD, S. Cognitive tasks in several modalities. In R. H. Williams, C. Tibbits, and W. Donahue (Eds.), Processes of aging, Vol, 1. New York: Atherton Press, 1963. Pp. 132-143.

DOTY, B. A. Age and avoidance conditioning. Journal of Gerontology, 1966, 21, 287-290.

GORDON, P. Diphenylhydantoin and procainamide: Normalization of sub-optimal learning behavior. In J. Wortis (Ed.), Recent advances in biological psychiatry, Vol. 10. New York: Plenum Press. Pp. 121-133.

INGLIS, J. Immediate memory, age and brain function. In A. T. Welford and J. E. Birren (Eds.), Behavior, aging and the nervous system, Springfield: Chas. Thomas, 1965. Pp. 88-113.

TOMAN, J. E. P. Drugs effective in convulsive disorders. In L. S. Goodman and A. Gilman, The pharmacological basis of the rapeutics, (3rd ed.) New York: Macmillan Co., 1965. Chap. 13.

TOMAN, J. E. P. Neuropharmacology of diphenylhydantoin. Paper presented at the Annual Meeting of American College of Neuropsychopharmacology, 1966.

WELFORD, A. T. Performance, biological mechanisms and age: A theoretical sketch. In A. T. Welford and J. E. Birren (Eds.), Behavior aging, and the nervous system. Springfield: Chas. Thomas, 1965. Pp. $3-20$.

1. Supported by NSF-URP Grant GY-2593. 